\title{
A RELAÇÃO UNIVERSIDADE-SOCIEDADE NA PERIFERIA DO CAPITALISMO
}

\section{Rogério Bezerra da Silva}

\section{Introdução}

Este trabalho busca responder, com base nos Estudos Sociais da Ciência e Tecnologia (ESCT), por que a relação universidade-sociedade no Brasil vem sendo reduzida à relação universidade-empresa. A relação da universidade brasileira com a sociedade nas três últimas décadas, no que diz respeito à produção de conhecimento científico e tecnológico (produção de C\&T, doravante), vem sendo alterada no sentido de privilegiar as demandas cognitivas (por conhecimento) de um ator específico: a empresa.

Com a crise econômica de 1973, o Brasil começou a perder sua capacidade de fomentar as instituiçôes de P\&D (universidades e institutos de $\mathrm{P} \& \mathrm{D})$. Nesse contexto, passaram a ganhar maior destaque no meio acadêmico os enfoques que atri-

Artigo recebido em 03/06/2010

Aprovado em 20/09/2011 buíam grande importância à interação das instituições de P\&D com outros atores, principalmente com as empresas privadas, como forma de ampliar a produção de C\&T nacional.

Baseadas nas experiências dos polos e parques de alta tecnologia surgidos nos Estados Unidos (Slicon Valley, Route 128), as primeiras formulaçôes acerca da relação universidade-empresa buscavam emular aqui a mesma interação que, se supunha, existia entre esses dois atores (universidade e empresa) naquele país. Nessa tentativa é que surgiu, entre as décadas de 1960 e 1980, no meio acadêmico brasileiro o que pode ser denominado marco normativo vinculacionista (Thomas, Davyt e Dagnino, 1997), que propunha açóes que pudessem levar as instituições de P\&D (especialmente as universidades) a serem centrais em um processo de oferta de tecnologia às empresas privadas.

Todavia, já em meados da década de 1980, se constatava que a maior parte da C\&T produ- 
zida nas instituições de P\&D brasileiras se orientava para as empresas estatais e não privadas. Isso porque a C\&T produzida por elas era de complexidade relativa maior do que aquela demandada pelas empresas privadas (nacionais e estrangeiras). A relação das instituições de $\mathrm{P} \& \mathrm{D}$ com as empresas privadas restringia-se, normalmente, a tarefas de controle de qualidade de processos e produtos e testes de resistência de materiais (Idem, ibidem).

Em meados dos anos de 1980 começou a ganhar força no Brasil (e na América Latina de forma geral) uma onda neovinculacionista (Idem, ibidem), vinculada ao enfoque da Economia da Inovação (EI, daqui em diante). Enfoque surgido nos países de capitalismo avançado como marco descritivo-explicativo de uma suposta realidade neles observada, mas que no Brasil foi utilizado como marco normativo para uma situação futura a que se pretendia chegar, que tinha a empresa privada como central no processo de inovação.

Os institutos de P\&D e, com maior destaque, as universidade públicas passaram então a ser considerados um fator indispensável para a promoção de uma competitividade sistêmica e, com isso, a produção de C\&T orientou-se crescentemente pela demanda cognitiva (presente e futura) das empresas (Dagnino, 2003).

Num quadro em que a competitividade de um país tende a ser reduzida à competitividade de suas empresas, estas passam a ser vistas cada vez mais como centrais para o crescimento econômico. No Brasil, já era, pois, esperada de membros da academia uma atitude pró-ativa nesse sentido, que se manifestou na conversão de atividades acadêmicas à ideia de que o estabelecimento de mecanismos institucionais de interação universidade-empresa seria uma tarefa coletiva: beneficiaria não apenas a universidade, que disporia de maiores recursos, mas também o conjunto dos atores envolvidos no processo de inovação (Gomes, 2001).

Outros dois enfoques, também surgidos nos países de capitalismo avançado em meados dos anos de 1990, logo reforçaram essa onda neovinculacionista no Brasil: o da New Production of Knowledge (Nova Produção do Conhecimento, ou NPC), e o da Triple Helix (Tripla Hélice, ou TH).
Os enfoques da EI, da TH e, em menor medida, da NPC foram, durante as três últimas décadas, redirecionados segundo pressupostos de que a relação entre a universidade e a sociedade no Brasil se reduziria ao papel que se esperava que a empresa viesse a desempenhar na sociedade.

Este trabalho está dividido, além desta introdução, em cinco seções. Na primeira, destaca-se o enfoque da EI, a fim de entender como se foi priorizando a noção de inovação e a importância da universidade nesse processo.

A segunda e terceira analisam os enfoques da NPC e TH e sua relação com a visão da EI. De certa forma, foi a justaposição desses enfoques que possibilitou a elaboração de justificativas teórico-metodológicas para que açōes (no âmbito acadêmico e governamental) orientadas à efetivação da relação universidade-empresa fossem executadas. Apesar do aparente consenso formado entre membros da academia sobre a necessidade e, até certo ponto, a indispensabilidade da relação da universidade com a empresa, há inúmeras abordagens críticas às perspectivas que se apoiam na NPC, na TH e na EI para defender essa relação.

A quarta seção apresenta os resultados da relação universidade-empresa no Brasil nas últimas décadas. Não obstante o que se pretendia, os resultados nesse sentido têm sido bastante modestos, ainda que o estímulo dessa relação permaneça. Na quinta seção, apresentam-se indícios que respondem à pergunta central deste artigo, qual seja, a defesa dessa relação por parte de uma parcela dos membros da academia tem o objetivo de aumentar os recursos públicos destinados às pesquisas universitárias, mesmo que as empresas não se interessem por elas.

O trabalho propõe ao final uma questão importante: apesar de o governo ser o maior financiador da P\&D universitária brasileira, por que sua demanda cognitiva também não está merecendo o devido destaque? Porém, isso que não será explorado aqui, mas, certamente, deverá ser tema de trabalhos futuros.

A novidade da discussão aqui empreendida é que, ao contrário do senso comum, a universidade está cada vez mais dependente dos recursos públicos para a manutenção de suas atividades de $\mathrm{P} \& \mathrm{D}$. 


\section{Da sociedade à empresa}

Entre as várias abordagens sobre as transformações recentes da relação da universidade com a sociedade, ganharam notoriedade aquelas que a reduzem ao papel da empresa como lócus do processo de inovação (Gunasekara, 2006).

Pelo menos desde os anos de 1970, já estava bastante difundido nos países de capitalismo avançado, mesmo que não amplamente aceitos por parcela dos membros de suas academias, os pressupostos daquilo que se convencionou chamar de Economia da Inovação, que teve como matriz teórica o que se conhece como Teoria da Inovação, cujo maior expoente foi Joseph Schumpeter. Até fins dos anos de 1970, nas suas primeiras formulações, a EI, com sua inspiração schumpeteriana, apresentava o "empresário empreendedor" como o ator fundamental no processo de inovação e, derivado deste, da competitividade das empresas. O empresário foi então descrito como o responsável por fazer com que as invenções se transformassem em inovações (produtos - bens ou serviços - e processos introduzidos no mercado).

Contudo, ao considerar a empresa como o lócus privilegiado da inovação e o empresário como ator direto do "progresso tecnológico", a EI nas suas primeiras formulações quase não se ateve à importância das açôes governamentais voltadas ao estreitamento da relação da universidade com a empresa (Dagnino, 2003). Isto porque a EI até então estava focada no entendimento daquilo que ocorria no ambiente da empresa e não no da universidade.

Foi em meados dos anos de 1980, com sua segunda formulação, que a EI passou a considerar o processo de aprendizagem científica e tecnológica também como fundamental na competitividade da empresa (Lundvall, 2001). Esta seria então descrita como resultado da combinação de elementos internos à empresa, como sua capacidade de gerar aprendizado científico e tecnológico com as universidades ou em seus próprios institutos de $\mathrm{P} \& \mathrm{D}$ ), ou como elementos externos, que seria seu contato direto com a produção e com o mercado.
A partir dessa segunda formulação é que a universidade começou a ganhar destaque como ator fundamental no processo de inovação. A empresa estaria se organizando em redes (locais ou globais), nas quais a universidade teria adquirido a função de qualificar os profissionais responsáveis pela produção de $\mathrm{P} \& \mathrm{D}$, indispensável ao processo de inovação (Idem, ibidem). Não tardou para que esse enfoque fosse utilizado como marco normativo para a relação universidade-sociedade no Brasil e, com ele, se privilegiasse $o$ atendimento das demandas cognitivas de um ator específico: a empresa.

No Brasil, no plano conceitual, a relação universidade-sociedade seria, a partir dos anos de 1990, gradativamente substituída pela relação universidade-empresa. Na prática, a universidade pública brasileira - diretamente ou por meio de incubadoras, parques e pólos tecnológicos implantados em sua cercania - passou a ser vista como ambiente favorável à interação de membros da academia com empresários, que supostamente seriam os responsáveis pela promoção da inovação tecnológica (Dagnino, 2010). Isso pode ser observado ao se fazer uma busca ${ }^{1}$ nos Censos do Diretório de Grupos de Pesquisa do CNPq à produção acadêmica dos grupos de pesquisa relacionada com a empresa (Gráfico 1).

\section{Gráfico 1}

\section{Produção Acadêmica Relacionada à Empresa}

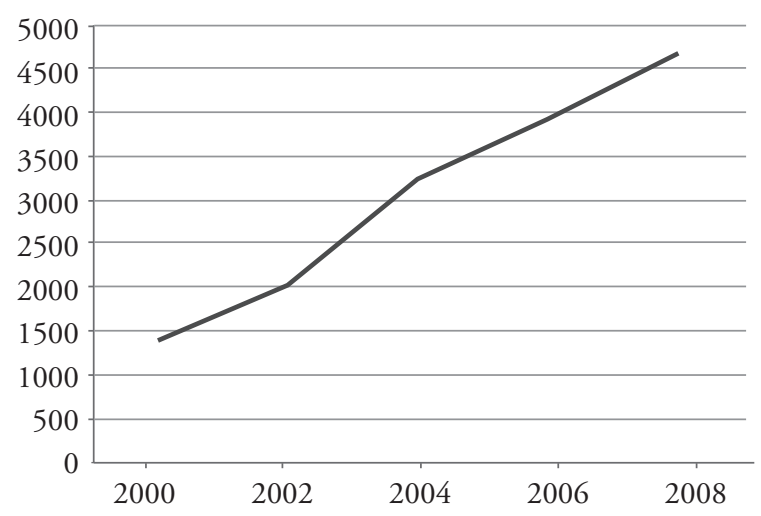

Fonte: Elaboração própria, a partir dos Censos do Diretório de Grupos de Pesquisa do CNPq. 
A ideia de que a produção de C\&T deve "passar" pela empresa privada para que ela possa beneficiar a sociedade está cada vez mais presente. Isso faz, de um lado, com que a relação universidade-sociedade seja orientada por ações voltadas à formação de mestres e doutores nas áreas de "ciências duras"; e, de outro, pelas açôes de apoio às empresas de alta tecnologia que, se supóe, poderiam contribuir com o desenvolvimento econômico do país.

\section{Três enfoques do neovinculacionismo}

Em meados dos anos de 1990, o discurso acerca da interação universidade-empresa foi reforçado no Brasil com a adoção, por parte dos membros da academia, de outros dois enfoques também surgidos nos países de capitalismo avançado: o da NPC (Nova Produção de Conhecimento) e o da TH (Tripla Hélice).

Segundo os partidários da NPC, desde as décadas de 1960 e 1970 estaria se desenvolvendo uma nova forma de se produzir C\&T, não mais restrita à universidade e que articulava diversos atores. Esse novo modo de produzir C\&T, denominado por Gibbons et al. (1994) Modo 2, estaria voltado ao atendimento da demanda dos ato- res sociais de forma geral, e das empresas privadas, em particular.

No Modo 2, as utilidades industrial e comercial são predominantes. Como resultado, ocorreria a introdução de altos graus de conflito, expectativas e incertezas na relação da universidade com a sociedade (ver Figura 1).

A inovação seria, tipicamente, o produto final de uma maior interação entre atores distintos, com localizações geográficas também distintas. Por isso, para a NPC, haveria cada vez mais a necessidade de integrar a universidade ao processo de inovação (Idem, ibidem).

Outra distinção entre os Modos 1 e 2 seria a relação entre Ciência ("ciências duras") e Política. A primeira adquire um valor político (politics) muito distinto do que ocorria no Modo 1, no qual era orientada pela "curiosidade e pelo desinteresse do cientista"; no Modo 2 é cada vez mais guiada por necessidades estratégicas associadas ao desenvolvimento econômico e social e a interesses políticos bem definidos.

O método científico, que no Modo 1 era entendido como "o caminho de se chegar à verdade", no Modo 2 perdeu importância, sendo substituído por várias metodologias criadas em função da utilidade prática e das necessidades estratégicas dos atores e das instituições envolvidas na produção de C\&T (Idem, ibidem).

\section{Figura 1}

\section{Modos de Produção de Conhecimento Científico}

\section{Modo 1 (linear)}

O conhecimento básico é produzido antes

e independentemente de aplicações.

Organização da pesquisa de forma disciplinar.

Organizações de pesquisa homogêneas.

Compromisso estrito com o conhecimento: os pesquisadores não se sentem responsáveis pelas possíveis implicações práticas de seus trabalhos.
Modo 2 (não linear)

O conhecimento é produzido no contexto das aplicaçōes.

Transdisciplinaridade.

Heterogeneidade e diversidade organizacional.

Accountability e reflexividade: os pesquisadores se preocupam e são responsáveis pelas implicações não científicas de seu trabalho.

Fonte: Schwartzman (2002). 
Parece que os possíveis vínculos e tensões entre a "pesquisa desinteressada" (pesquisa básica) e a "interessada" (pesquisa aplicada) têm sido objeto de constantes discussões sobre a relação da universidade com a sociedade. Isso porque essa discussão está presente também no enfoque que, mais do que o da NPC, tem influenciado essa relação no Brasil: o da TH.

Um levantamento ${ }^{2}$ feito na base de dados do Google Scholar (que armazena literatura acadêmica de forma geral) permite verificar a importância que esses enfoques vieram adquirindo desde meados dos anos de 1990 na produção acadêmica brasileira (ver Gráfico 2). Como se pode observar, as referências à $\mathrm{TH}$, além de apresentarem tendência de crescimento, são maiores do que à NPC.

Também para os partidários da $\mathrm{TH}$, estaria ocorrendo desde os anos de 1960 um aumento da sinergia entre universidade e empresa. Tal como alegam os autores alinhados à $\mathrm{TH}$, desde então o número de contratos entre empresas e universidades com vistas ao desenvolvimento de atividades conjuntas vem aumentando (Etzkowitz, 2002). As universi- dades incorporaram o objetivo do desenvolvimento econômico às suas já clássicas atividades de ensino $\mathrm{e}$ pesquisa (Etzkowitz e Leydesdorff, 1995).

Para a TH, a despeito do fenômeno da globalização, as estratégias de produção de C\&T não deveriam seguir um único padrão. Elas deveriam estar também subordinadas às especificidades locais, com seus distintos desenvolvimentos históricos (Etzkowitz, 2002). O governo deveria incentivar a criação de "nichos locais" de inovação tecnológica, que poderiam assegurar a ele uma posição de destaque na divisão internacional do trabalho da economia global (Idem, ibidem).

A maior importância conferida aos atributos locais, juntamente com a adaptação a situações contingenciais advindas da globalização, faria com que a universidade assumisse novas funçôes nas redes de produção de C\&T, para além da qualificação profissional (Idem, ibidem). Na medida em que a C\&T fosse se tornando cada vez mais um insumo importantíssimo para o desenvolvimento socioeconômico, a universidade tornar-se-ia um ator social de destaque (Idem, ibidem).

\section{Gráfico 2}

\section{Referências à NPC e à TH}

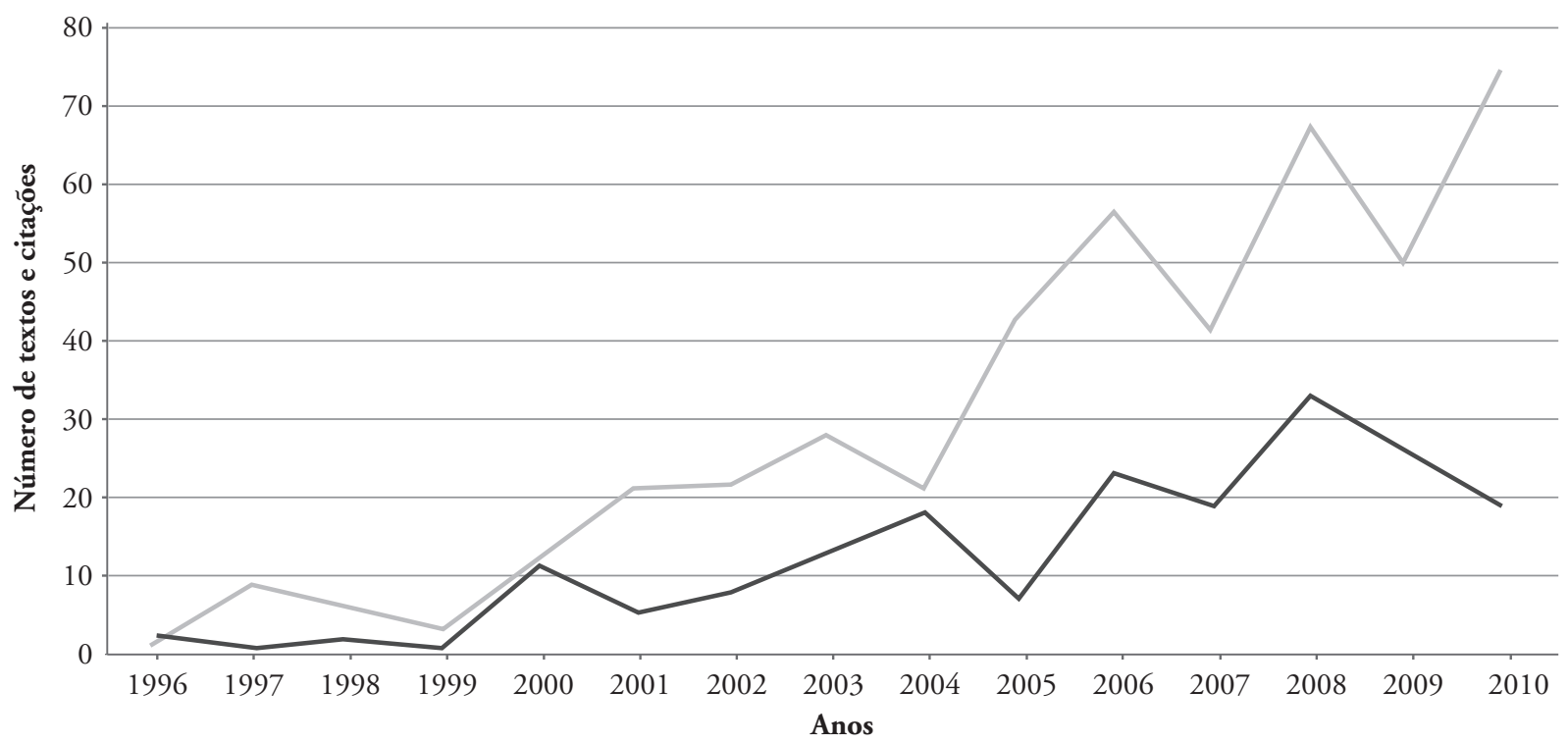


Nota-se que, acompanhando as mudanças econômicas e tecnológicas ocorridas desde o fim da Segunda Guerra Mundial, surge um enfoque econômico que busca analisar e orientar o comportamento da empresa diante dessa transformação - EI - e outros dois enfoques sociológicos - NPC e TH - que tratam da adaptação da universidade a esse contexto.

Esses três enfoques complementam-se em alguns aspectos. Entre eles, merece destaque a atenção que dão à: i) necessidade da interação entre atores (universidade, empresa e governo) para seus mútuos fortalecimentos; ii) diluição de barreiras que separam suas competências; e iii) empresa como ator fundamental na produção da C\&T. Uma característica que aproxima ainda mais a TH da EI é que ambas defendem a proteção da P\&D produzida, que poderia ocorrer por meio do registro de patentes. A NPC, embora levante essa questão, não toma uma posição muito clara a respeito. Também podem ser destacadas outras diferenças e semelhanças entre os três enfoques destacados no Quadro 1.

Porém, apesar do aparente consenso formado entre membros da academia dos países de capitalismo avançado e dos de capitalismo periférico sobre a necessidade e, até certo ponto, a indispensabilidade da relação da universidade com a empresa, há inúmeras abordagens críticas aos enfoques que se apoiam na NPC, na TH e na EI para defender essa relação.
Dentre as críticas especialmente voltadas à NPC e à TH, ganhou destaque a formulada por Shinn (2002), a partir da perspectiva dos estudos sociológicos franceses sobre a pesquisa tecnológica. Segundo Shinn, NPC e TH não consideram dois dos aspectos mais importantes na produção e na difusão do conhecimento. Em primeiro lugar, eles não reconhecem que a universidade, o governo e a empresa atendem também a ditames locais e não somente a regras globais. Além disso, disciplinas e subdisciplinas científicas funcionam de maneira distinta em instituições nacionais diferentes, e isto ocorre também no âmbito do mercado. $\mathrm{O}$ segundo aspecto é relativo à maneira como NPC e TH tratam um dos conceitos-chave sociológicos: o de diferenciação. A NPC sugere que as diferenciações (como a divisão do trabalho) seriam coisas do passado. A TH, mesmo com uma abordagem um tanto distinta da NPC neste aspecto, adota os modelos clássicos de diferenciação e integração, interpretando-os em um marco coevolucionista. Porém, na prática, a NPC projeta grandes ciclos de integração, neodiferenciação, neointegração e assim sucessivamente, em uma infinita repetição coevolucionista (Idem, ibidem).

No Brasil, também há muitas vozes dissonantes em relação à "partitura" fundamental baseada nos princípios da EI, da TH e da NPC. Como "coristas" mais expressivos desse grupo,

\section{Quadro 1}

Diferenças e Semelhanças entre os Enfoques

\begin{tabular}{|c|c|c|c|}
\hline $\begin{array}{ll}\text { Características } & \text { Enfoques } \\
\end{array}$ & EI & NPC & TH \\
\hline Foco no processo de produção da: & $\begin{array}{l}\text { Tecnologia } \\
\text { ("ciência aplicada") }\end{array}$ & $\begin{array}{l}\text { Ciência } \\
\text { ("ciência básica") }\end{array}$ & $\begin{array}{l}\text { Tecnologia } \\
\text { ("ciência aplicada") }\end{array}$ \\
\hline Matriz teórica: & Econômica & Sociológica & Sociológica \\
\hline Privilegia o ator: & Empresa & Universidade & Universidade-Empresa \\
\hline Espaço de incidência da política é: & Global e Local & Global & $\begin{array}{l}\text { Local } \\
\text { (Arranjos institucionais) }\end{array}$ \\
\hline $\begin{array}{l}\text { O direito de propriedade } \\
\text { intelectual: }\end{array}$ & Deve ser garantido & $\begin{array}{l}\text { Levanta a questão, mas } \\
\text { não toma posição }\end{array}$ & Deve ser garantido \\
\hline
\end{tabular}

Fonte: Elaboração própria. 
encontram-se os "cientistas duros", mas, outras vozes das humanidades já se integraram ao "coro". Como destacado por Dagnino (2003), esses enfoques apresentam outras duas características que os aproximam. Em primeiro lugar, ambos são oriundos de uma mesma visão da conjuntura internacional (globalização) e, também, de uma mesma matriz ideológica (neoliberalismo), que privilegia o mercado como ente regulador principal da relação da universidade com a sociedade. Em segundo, são francamente complementares. Foram construídos a partir de uma perspectiva que privilegia a formulação de proposições que funcionem ao mesmo tempo como agenda de pesquisa voltada à inovação e como conclusões provisórias que orientem a elaboração da Política de Ciência e Tecnologia (PCT). Além disso, outras críticas afirmam que se as universidades fossem inseridas na lógica da produção de C\&T para o mercado, ou mesmo para o Estado, elas se submeteriam a mecanismos de controle que afetariam substantivamente sua autonomia acadêmico-científica (Trindade, 1999). Além disso, vale lembrar que a relação universidade-sociedade defendida pelos partidários desses enfoques privilegia apenas a produção de C\&T que direta ou indiretamente pode incrementar a concorrência intercapitalista (Chauí, 1999).

Para essas vozes dissonantes, a universidade é uma instituição social (científica e educativa), cuja identidade está fundada em princípios, valores, regras e formas de organização inerentes a ela. Seu reconhecimento e sua legitimidade social vinculam-se, historicamente, à sua capacidade autônoma de lidar com ideias, buscar o saber, descobrir e inventar o conhecimento (Catani e Oliveira, 1999).

Outra crítica, não ligada especificamente a esses enfoques, incide sobre a política que eles ajudam a orientar: a PCT. Algo pouco percebido pelos cientistas políticos de forma geral é que a PCT, para além de seu caráter de policy (política pública), possui também um caráter de politics (relaçôes de poder), em que os atores (especialmente membros da academia) entram em disputa para viabilizar seus projetos políticos (Dagnino, 2007). E, dentre esses projetos, destacam-se aqueles que privilegiam as demandas cognitivas da empresa.
Dessa forma, pode-se afirmar que: i) os enfoques não apresentam evidências empíricas dos temas que abordam; ii) não desenvolvem um método de análise da realidade observada; iii) foram utilizados para orientar a elaboração de políticas a partir de uma análise frouxa da realidade observada; e iv) reduzem a sociedade à dinâmica que se espera que a empresa privada exerça.

\section{Três enfoques, três atores e uma orientação}

São destacados nos enfoques da EI, da NPC e da TH três atores fundamentais que, somente para os fins analíticos deste trabalho, são destacados com papéis distintos na dinâmica de produção de C\&T e na relação universidade-sociedade: Universidade, Empresa e governo.

\section{O papel da universidade}

Até meados da década de 1980, a universidade possuía, segundo a EI, o papel de formadora de pessoal qualificado que atuaria nos institutos de P\&D das empresas. Porém, desde então, as universidades assumiram também um novo papel, qual seja, o de comercializar tecnologias demandadas pelo mercado. Nos últimos trinta anos, a universidade tornou-se a grande promovedora do desenvolvimento tecnológico, contribuindo para o aumento da produtividade (Ruiz, 2005).

Os avanços científicos registrados ao longo do século XX levaram a universidade a tratar de forma mais objetiva seu papel de investigadora, orientando parte de suas atividades ao atendimento das demandas econômicas. Ela estaria se convertendo não somente em um ator capaz de dar soluções a problemas teóricos e abstratos, mas também de resolver problemas específicos e aplicados (Idem, ibidem).

Para a NPC, a produção de C\&T não é mais exclusividade da universidade, abrindo espaço para os institutos de P\&D privados (de propriedade das empresas). A expansão internacional da educação superior estaria levando, pois, a um aumento do número de lugares potenciais em que se poderia produzir C\&T (Gibbons et al., 1994). As novas formas de produção 
de $C \& T$, à medida que são difundidas, deixam mais porosas as velhas linhas que demarcavam as fronteiras entre as disciplinas e as instituiçōes. Nesse caso, a universidade poderia adotar "valores" da cultura empresarial, dando lugar, assim, a um tipo completamente novo de empresário, o acadêmico (Idem, ibidem).

De um lado, EI e NPC aproximam-se do enfoque da TH quando destacam que o papel da universidade é o de formar pessoal qualificado para atuar em atividades de P\&D nas empresas. De outro, principalmente EI e TH divergem no que diz respeito ao papel da universidade como empreendedora (criadora de mecanismos que possibilitem aos membros da academia se inserir no "mundo dos negócios"). De acordo com o enfoque da TH, o empreendedorismo da universidade ocorre em dois sentidos: 1) de preparar os alunos (graduandos e pós-graduandos) para agir e pensar por conta própria, despertando neles sua criatividade, liderança e visão de futuro voltada à inovação, para que, com isso, possam ocupar um espaço no mercado; e 2) apoio à criação de empresas de propriedade de acadêmicos (professores ou alunos), o que poderia ser feito por meio da criação de incubadoras de empresas nas universidades.

\section{O papel da empresa}

Segundo o enfoque da EI, a empresa é, a um só tempo, depositária e produtora de C\&T, desenvolvendo novos produtos e processos produtivos (Antonelli, 2002). Essa visão considera a empresa central no processo de inovação. A criação de empresas de alta tecnologia seria indispensável ao crescimento e ao desenvolvimento econômico das localidades e regióes, pois elas se constituem em loci privilegiados do processo de inovação.

Para a NPC, as empresas intensificam a criação de suas próprias instituiçóes de $\mathrm{P} \& \mathrm{D}$ para dar conta do conhecimento necessário, mesmo que a operacionalização deles dependa de parcerias com as universidades (Gibbons et al., 1994). O papel fundamental da empresa seria, então, o de fazer com que a C\&T produzida em seu instituto de $\mathrm{P} \& \mathrm{D}$ ou na universidade, chegasse ao mercado. Isso porque as aplicaçôes comerciais da C\&T não poderiam ocorrer na universidade (Idem, ibidem). Somente a empresa teria competência para tornar essa aplicação efetiva.

Para a TH, a empresa adquire o mesmo papel da universidade. Por meio de seus institutos de $\mathrm{P} \& \mathrm{D}$, ela produziria C\&T e também formaria pessoal qualificado (Etzkowitz, 2002). A empresa somente não teria a função de formar pesquisadores, função que caberia à universidade.

\section{O papel do governo}

Segundo o enfoque da EI, a influência do governo na interação interinstitucional e na regulação do comportamento dos atores e de suas formas de concorrência ganhou maior importância na última década. O governo, por meio de políticas públicas, pode ajudar as instituiçōes a "desprenderem-se" do passado e adquirirem trajetórias de desenvolvimento originais (Cimoli et al., 2007). Portanto, para os partidários da EI, apoiar politicamente o desenvolvimento de novas tecnologias, de setores e de firmas específicas é da competência governamental. $\mathrm{O}$ governo deveria fomentar a produção de $\mathrm{C} \& \mathrm{~T}$ e possibilitar sua exploração econômica, de maneira consistente com os interesses de múltiplos atores (Idem, ibidem).

O Modo 2 cria novos desafios para o governo. Segundo os partidários da NPC, o governo deve elaborar políticas públicas que delimitem as competências das empresas e das instituiçôes de $\mathrm{P} \& \mathrm{D}$, ficando as primeiras responsáveis pelo patenteamento e pela comercialização e, as segundas, pelas pesquisas que contribuem para a criação de inovação (Gibbons et al., 1994).

O papel do governo, no enfoque da $\mathrm{TH}$, é não só o de instituir uma política que possa dar conta de articular instituiçôes à produção de $\mathrm{C} \& \mathrm{~T}$, assim como o de criar uma sobreposição de redes e organizaçôes trilaterais, com finalidade de desenvolver novas ideias que resultem em inovações (Etzkowitz, 2002).

Embora haja distinções, os três enfoques destacam o papel central do governo como regulador ou facilitador das relaçóes entre universidade e empresa. Esses atores, assim, poderiam se rearranjar de forma mais conveniente à produção de C\&T. 


\section{Resultados da interação universidade- -empresa no Brasil}

Os enfoques da NPC, da TH e da EI, como observado, têm apontado para a necessidade crescente de a universidade poder e, mais que isso, dever contribuir para o desenvolvimento econômico do país. Debates até então existentes acerca da relação entre a universidade e a sociedade estão sendo, paulatinamente, substituídos por discursos que entendem a inovação não mais como uma opção para a universidade, mas como uma exigência (Cardoso, 2001).

Entretanto, um olhar mais atento para a realidade brasileira mostra que o ator econômico que aqui é chamado de empresa não é exatamente o que nos países de capitalismo avançado recebe este nome, isto é, não cumpre as mesmas funções. Ao adotar acriticamente o marco de referência gerado naqueles países para tratar do que ocorre na periferia do capitalismo, os membros da academia brasileira incorreram no "pecado" epistemológico de nomear da mesma forma objetos que exprimem significados diversos (Dagnino, 2004). Além disso, ao contrário do que acredita o meio acadêmico - ou seja, de que o lugar da ciência e da educação é a universidade e o lugar do desenvolvimento ou da demanda de tecnologia, a empresa -, as universidades públicas não seriam formadoras de pesquisadores e engenheiros, nem gerenciariam as inovações tecnológicas.

Se nos detivermos na política industrial brasileira a partir da década de 1970 , fica evidente que o Estado não tem tido o poder de articular e coordenar em âmbito nacional as interações entre empresas e universidades com vistas à inovação tecnológica, tal como ocorre em países de capitalismo avançado. Os resultados nesse sentido, como veremos a seguir, têm sido bastante modestos. Existe um grau razoável de concordância entre o pensamento oficial e aquele alternativo acerca do diagnóstico do agravamento da situação de debilidade da interação entre o potencial de C\&T e o desenvolvimento econômico a ele associado. Todavia, apesar do agravamento dessa situação, não é muito difícil notar o quanto o discurso acerca da necessidade dessa interação tem se intensificado entre as instituições que compõem o sistema de C\&T bra- sileiro (universidades, institutos de $\mathrm{P} \& \mathrm{D}$, instituições de fomento, ministérios etc.).

Basta uma análise dos gastos do Ministério de Ciência e Tecnologia (MCT) com seu Plano de Ação em Ciência, Tecnologia e Inovação (PACTI) entre os anos de 2007 e 2010, para que se confirme a relevância, hoje, do discurso acerca da interação universidade-empresa. Dos quatro eixos desse Plano, ${ }^{3}$ dois deles - I) expansão e consolidação do sistema nacional de ciência, tecnologia e inovação e II) promoção da inovação tecnológica nas empresas, diretamente voltados à interação universidade-empresa - receberam 60\% dos recursos (R\$ 2.7 bilhões) (MCT, 2010).

\section{Comportamento da empresa}

As Pesquisas de Inovação Tecnológica (Pintec) de 2003 e 2008 (IBGE, 2003 e 2008) mostram que apenas $10 \%$ das cerca de 30 mil empresas locais, que adotaram internamente uma inovação ou lançaram no mercado algum produto ou processo novo, estabeleceram, neste período, parcerias com universidades e institutos de P\&D. E, o que é mais significativo, $70 \%$ delas consideraram irrelevantes ou de baixa importância esta relação.

Talvez o que melhor questione a importância da pesquisa universitária para a empresa seja o ínfimo aproveitamento desta em relação à estrutura pública de $\mathrm{P} \& \mathrm{D}$ e pós-graduação do país. Entre 2006 e 2008, enquanto o Brasil formava quase 30 mil mestres e doutores por ano nas áreas de "ciências duras", que os partidários daqueles enfoques apresentam como sendo os profissionais demandados pelas empresas, o número dos que ali produzem $P \& D$ aumentou em três anos apenas cerca de $1,5 \%$, mais exatamente de 4.330 para 4.398 profissionais (IBGE, 2008), o que dá uma taxa de absorção anual de 0,07\% (68/90.000), ao passo que, nos Estados Unidos, $80 \%$ dos pós-graduados formados a cada ano vão para a empresa produzir P\&D (taxa mil vezes maior) (Unesco, 2010).

Segundo dados das Pintec (IBGE, 2005 e 2008), enquanto $5,6 \%$ das empresas realizaram atividades internas de P\&D em 2005, essa proporção caiu para 4,2\% em 2008. Os gastos totais 
com atividades de inovação despendidos pelas indústrias de transformação, que eram de 2,8\% do faturamento em 2005, retrocederam para 2,6\% em 2008, enquanto a parcela da despesa destinada especificamente à $\mathrm{P} \& \mathrm{D}$ intramuros ficou em $0,6 \%$ do faturamento em 2008.

A proporção de empresas que se dedicaram a atividades de P\&D caiu de 3,9\% para 3,4\% das de pequeno porte, de $16,2 \%$ para $7,9 \%$ das de médio porte e de $44,9 \%$ para $36,3 \%$ das de grande porte entre 2005 e 2008 (Kupfer, 2010).

É preciso também desvelar um mito que segue fundamentando grande parte das medidas que tentam vincular universidades a empresas. Diz respeito à mobilização do potencial de $\mathrm{P} \& \mathrm{D}$ pública que se pode esperar da empresa privada (doméstica ou estrangeira). Nos Estados Unidos, por exemplo, entre 1994 e 2004, apenas $1,1 \%$ do que a empresa privada investiu em P\&D foi contratado nas universidades (Science and Engineering Indicators, 2006). Se esses dados referem-se ao país onde aqueles enfoques foram desenvolvidos, o que então se pode esperar que aconteça aqui no Brasil?

Como destacado por Furtado (1972 e 1974) já na década de 1970, as empresas estrangeiras tinham o controle quase absoluto das indústrias de bens de consumo duráveis, químico-farmacêutica e de equipamentos em geral, que, em conjunto, eram as que mais se expandiam e mais inseriam inovações em sua produção (Furtado, 1972).

Segundo Costa (2003), entre as empresas brasileiras, as de capital estrangeiro foram as que mais investiram em P\&D. Todavia, se comparadas às suas matrizes no exterior, era relativamente pequeno o esforço tecnológico das filiais brasileiras. Observados cinco setores industriais brasileiros com maior participação estrangeira, constatou-se que os esforços tecnológicos das filiais foram $70 \%$ menores do que os de suas matrizes no segmento farmacêutico, $10 \%$ no de máquinas e equipamentos, $60 \%$ no de materiais e equipamentos eletrônicos, $31 \%$ no de instrumentos médicos, óticos e de precisão e de $62,5 \%$ no de veículos automotores e autopeças.

Como o processo de diferenciação e criação de novos produtos apoia-se, do lado da demanda, na adoção dos hábitos de consumo dos países de ca- pitalismo avançado, as empresas brasileiras (estrangeiras e domésticas) utilizam, como constatado pelas Pintec, tecnologias transferidas do exterior para produzi-los. Nesse caso, de acordo com que Biato, Guimarães e Figueiredo (1973) haviam observado na década de 1970, a inovação constitui-se apenas em produzir internamente o bem já fabricado nos países de capitalismo avançado.

\section{Comportamento do governo}

Um olhar mais atento para a política industrial brasileira mostraria o quão distante ela estava, já na década de 1970, de uma coordenação nacional. Segundo Furtado (1974), era considerável a dificuldade de coordenação da economia no plano interno devido à forma como ela vinha sendo articulada à economia internacional, fortemente influenciada pelas empresas transnacionais.

Outro ponto importante que dificulta a coordenação do governo sobre as atividades de inovação é a correlação de forças entre ele, as empresas e a universidade. Pelo menos desde o início do "processo de substituição de importações", tal correlação tem sancionado uma crescente e brutal concentração de poder econômico nas mãos das empresas (de capital nacional e estrangeiro) que têm muito pouco interesse na C\&T localmente produzida e na contratação de pesquisadores formados (Dagnino e Thomas, 1999). Apesar dos esforços governamentais, como, por exemplo, a implementação da Lei de Informática, do programa de subvenção econômica ou do financiamento de pesquisas conjuntas com universidades, as empresas demonstram pouco interesse na $\mathrm{P} \& \mathrm{D}$ produzida localmente como mecanismo de aumento de sua competitividade. Como mostra a Pintec de 2008 (IBGE, 2008), entre 2006 e 2008 o principal incentivo público utilizado pelas empresas inovadoras foi o finanaciamento para a compra de máquinas e equipamentos $(14,2 \%$ do total de recursos disponíveis); os menos utilizados foram o recém-criado instrumento de subvenção econômica à empresa $(0,5 \%)$ e o financiamento de projetos de $\mathrm{P} \& \mathrm{D}$ e inovação tecnológica em parceria com universidades ou institutos de pesquisa $(0,8 \%)$. 


\section{Comportamento da universidade}

Ao contrário do que se supunha em relação aos países de capitalismo avançado, a universidade brasileira não é formadora de pesquisadores e engenheiros, nem produz as inovações necessárias às empresas. Isso porque as empresas brasileiras permanecem, em sua maioria, filiais de firmas estrangeiras, as quais possuem programas de investimento próprios. Dessa forma, a influência de tais empresas na produção de $\mathrm{C} \& \mathrm{~T}$ no Brasil tem sido muito baixa.

Dados do USPTO (United States Patent and Trademark Office) a respeito de patentes de 182 empresas transnacionais mostram que, entre 1981 e 2001, a maior parte das atividades inovadoras estava concentrada em seus países sede. Quando tais atividades eram internacionalizadas, direcionavam-nas a Europa, Japão ou Estados Unidos. Entre 1999 e 2001, aproximadamente $97 \%$ das patentes da USPTO possuíam ao menos um inventor localizado na Europa, nos Estados Unidos ou no Japão (Minin, 2005 apud Cassiolato e Zucoloto, 2006).

Uma vez que a demanda da sociedade brasileira por novos produtos ou processos reproduz o padrão de consumo dos países de capitalismo avançado, ela se satisfaz com a transferência de tecnologias importadas. Ou seja, para atender essa demanda, as empresas brasileiras não necessitam investir em $P \& D$. Admitindo que os membros da academia aconselhassem o governo brasileiro a adotar uma política de manutenção e estímulo às universidades e à $\mathrm{P} \& \mathrm{D}$, paralelamente a um indispensável programa intensivo de educação básica, ainda assim permaneceria uma dificuldade fundamental, a saber, a utilização dos cientistas (pesquisadores) pelas empresas brasileiras (Leite Lopes, $s / d$ ). Se essas empresas operam com base na $P \& D$ realizada no exterior, os pesquisadores formados pelas universidades brasileiras não teriam muitas oportunidades de emprego em hipotéticos institutos de P\&D de propriedade das empresas estrangeiras ou domésticas. As empresas brasileiras não estão, portanto, interessadas em estabelecer vínculos com as universidades.

Os indicadores de publicação de artigos em periódicos indexados, utilizados usualmente para avaliar o potencial científico, e de registros inter- nacionais de patentes, para a avaliação da capacitação tecnológica, comparados aos dados da Coreia do Sul, por exemplo, indicam a baixa capacidade de utilização do potencial científico do Brasil no que concerne a inovação tecnológica. Entre 2007 e 2008 , a produção científica brasileira cresceu $56 \%$, e o país passou da $15^{\text {a }}$ para a $13^{\text {a }}$ colocação no ranking mundial de artigos publicados em revistas especializadas - apenas uma posição acima da Coreia do Norte, que ocupava a $12^{\mathrm{a}}$ colocação. No aspecto quantitativo, o Brasil foi o país que mais cresceu na lista das vinte naçóes com mais artigos publicados em periódicos científicos indexados pelo Information Science Institute - ISI (MEC, 2010). Todavia, em se tratando de sua capacidade tecnológica, o Brasil não teve o mesmo desempenho. Segundo a Organização Mundial da Propriedade Intelectual (Wipo, em inglês), em 2010 os pedidos brasileiros de registros internacionais de patente caíram 14\%. Já a Coreia do Sul teve um aumento de $20 \%$ no mesmo ano. Enquanto o Brasil caiu de $23^{\circ}$ para $24^{\circ}$ lugar no ranking entre 142 países membros do Tratado de Proteção de Patentes da Ompi, a Coreia manteve-se na quarta posição (Wipo, 2010).

Também deve ser destacado o baixo potencial de captação de recursos pelas instituições de $\mathrm{P} \& \mathrm{D}$ via contratação de projetos de $\mathrm{P} \& \mathrm{D}$ com a empresa privada. Nos Estados Unidos, o governo foi responsável, entre 1994 e 2004, em média por $87 \%$ da receita alocada em $\mathrm{P} \& \mathrm{D}$ pelas instituições públicas. Nesse mesmo período, a empresa privada foi responsável, em média, por apenas $6,7 \%$ da receita alocada em P\&D dessas instituiçôes (Science and Engineering Indicators, 2006). Isso sugere que o potencial de captação de recursos pela universidade brasileira é ainda menor do que o observado em países como os Estados Unidos.

Esses apontamentos revelam as características da relação universidade-empresa no Brasil vis-à-vis o panorama internacional. Mesmo diante dos diversos apontamentos que já haviam sido feitos nas décadas de 1960 e 1970 sobre as debilidades dos três atores destacados pela EI, num primeiro momento, e pela TH e NPC, mais recentemente, no contexto brasileiro a relação universidade-sociedade continua orientada por esses enfoques. 


\section{Financiamento da C\&T}

Se a relação universidade-sociedade no Brasil está sendo reduzida à relação universidade-empresa, isso quer dizer então que a empresa é a responsável por grande parte do financiamento das pesquisas universitárias. Todavia, mais do que uma relação, a empresa vem se constituindo num discurso.

De acordo com dados do MCT, entre 2000 e 2009 os governos estaduais e o federal foram responsáveis por $53 \%$ em média do total despendido em C\&T no Brasil. As empresas inovadoras (que realizaram alguma atividade de $\mathrm{P} \& \mathrm{D}$ nesse período) foram responsáveis por $47 \%$ do total (disponível em $<$ mct.gov.br $>$ ). Se pudéssemos separar o gasto das empresas privadas e o das estatais em $P \& D$, o dispêndio público seria ainda maior. As Pintec de 2003, 2005 e 2008 indicam que, entre 2000 e 2008, 50\% do dispêndio empresarial em P\&D foram aplicados na aquisição de máquinas e equipamentos. Ou seja, daqueles $47 \%$ somente $23,5 \%$ foram despendidos pelas empresas inovadoras em atividades que, de alguma forma, necessitavam da universidade. Dessa forma, dos 100\% do dispêndio em C\&T no Brasil (somados os gastos governamental e empresarial) em atividades que, de alguma forma, necessitariam da universidade, $70 \%$ é de origem governamental e $30 \%$ empresarial (pública e privada).

Foram investidos pela Finep entre 2003 e 2006 cerca de $\mathrm{R} \$ 600$ milhões em projetos que visavam promover a cooperação entre instituiçôes de $\mathrm{P} \& \mathrm{D}$ e empresas. A contrapartida das empresas foi da ordem de R \$ 200 milhōes. Ou seja, para cada R \$3 investidos pela Finep, as empresas investiam $\mathrm{R} \$ 1$ (Bagattolli, 2008).

A análise sobre a receita de pesquisa da Unicamp ajuda a identificar a origem dos recursos destinados à $\mathrm{P} \& \mathrm{D}$ das universidades públicas brasileiras. Brisolla et al. (1997) analisaram a composição de 732 contratos da Universidade no período

Quadro 2

Financiamento da P\&D na Unicamp nos Períodos 1981-1995 e 2000-2007

\begin{tabular}{llllll}
\hline Categoria do Financiador & Frequência & $\begin{array}{l}\text { Duração } \\
\text { média } \\
\text { (meses) }\end{array}$ & $\begin{array}{l}\text { Valor } \\
\text { médio } \\
\text { (R\$ mil) }\end{array}$ & $\begin{array}{l}\text { Volume Médio de Recursos } \\
\text { (R\$ milhóes) }\end{array}$ \\
\hline Períodos & & $\mathbf{1 9 8 1 - 1 9 9 5}$ & & $\mathbf{1 9 8 1 - 1 9 9 5}$ & $\mathbf{2 0 0 0 - 2 0 0 7 *}$ \\
\hline Agências de Financiamento & 201,0 & 30,7 & 588,0 & 118,2 & 117,3 \\
\hline Empresa Privada & 195,0 & 16,3 & 82,6 & 16,1 & 13,8 \\
\hline Empresa Estatal & 164,0 & 21,1 & 315,9 & 51,8 & 10,3 \\
\hline Institutos Públicos de P\&D & 55,0 & 13,0 & 27,2 & 1,5 & $s / d$ \\
\hline Administração pública Federal & 39,0 & 12,6 & 102,0 & 34,0 & 15,6 \\
\hline Administração pública Estadual & 35,0 & 12,3 & 277,5 & 9,7 & 5,8 \\
\hline Administração pública Municipal & 15,0 & 13,8 & 130,6 & 2,0 & 3,2 \\
\hline Instituições Internacionais & 14,0 & 32,4 & 148,5 & 2,1 & 2,5 \\
\hline Universidades e ONGs Nacionais & 14,0 & 17,4 & 180,0 & 2,5 & $s / d$ \\
\hline Financiamento Próprio & $s / d * *$ & $s / d$ & $s / d$ & $s / d$ & 2,5 \\
\hline Fundos de C\&T & $s / d$ & $s / d$ & $s / d$ & $s / d$ & 16,2 \\
\hline Totais & 732,0 & 21,0 & 325,0 & 237,9 & 187,2 \\
\hline
\end{tabular}

* O volume médio de recursos no período de 2000 a 2007 foi calculado com base nos recursos alocados em P\&D na

Unicamp. ${ }^{* *} \mathrm{~s} / \mathrm{d}$ (sem dados).

Fonte: Para o período 1981-1995, ver Brisolla et al., 1997; para o período 2000-2007, ver Unicamp, 2007. 
de 1981 a 1995. Entre eles, 27,5\% foram firmados com agências de financiamento do governo, $26,6 \%$, com empresas privadas e $22,4 \%$, com empresas estatais. Essas três categorias respondiam por mais de três quartos do número de projetos. Se somadas as administrações públicas federal, estadual e municipal, elas representam $12,2 \%$ dos contratos da Unicamp nesse período.

O maior valor médio dos projetos, entre 1981 e 1995, foi financiado pelas agências governamentais $(\mathrm{R} \$ 588 \mathrm{mil})$; o segundo maior valor médio foi o das empresas estatais (R $\$ 316$ mil). Também merece destaque as administraçōes públicas federal, estadual e municipal que, individualmente ou somadas, tiveram um valor médio de projetos firmados com a Unicamp maior que o das empresas privadas. $\mathrm{O}$ caso da administração pública estadual é o que mais se destaca. $\mathrm{O}$ valor médio de seus projetos com a Universidade foi de $\mathrm{R} \$ 277,5$ mil, ou sejam 3,4 vezes superior ao valor médio dos projetos das empresas privadas com a Unicamp (Quadro 2).

Como indica o Quadro 2, as agências de financiamento foram responsáveis, no período de 1981 a 1995, por um montante de $\mathrm{R} \$ 118$ milhôes destinados à Universidade, o que corresponde a 50\% de seus recursos extra-orçamentários. No segundo período, 1981-1995, elas continuaram sendo os maiores financiadores da P\&D da Unicamp, tendo inclusive sua participação se elevado para $63 \%$ do total de recursos. No primeiro período, as empresas estatais respondiam por $21 \%$ do financiamento da P\&D da Unicamp; já no segundo, sua participação foi reduzida a 5,5\% do total. As administraçōes públicas federal, estadual e municipal, somadas, tiveram papel de destaque no financiamento no primeiro período analisado. Elas foram responsáveis por $19 \%$ do total de financiamento à $\mathrm{P} \& \mathrm{D}$ da Unicamp. Já no segundo período, representaram 13\% do total, participação superior aos $6,8 \%$ e $7,4 \%$ das empresas privadas, nos respectivos períodos. Se somados os financiamentos públicos, eles representaram no primeiro período $92 \%$ do total da $P \& D$ da Unicamp; e 93\%, para o segundo período.

Mais recentemente, ganhou relevância os contratos e parcerias da Agência de Inovação da Unicamp. Em 2006, nas atividades de articulação de convênios e termos aditivos de projetos colaborati- vos de pesquisa entre Unicamp, empresas e órgãos de governo, a Agência de Inovação apoiou a busca e a negociação, bem como a tramitação e a assinatura de 75 instrumentos jurídicos (projetos), totalizando a quantia de $\mathrm{R} \$ 11,6$ milhôes. Desses 75, 27 correspondem a projetos de $\mathrm{P} \& \mathrm{D}$, sendo que os dois maiores financiadores foram a Receita Federal e o laboratório farmacêutico Aché, com montantes de $\mathrm{R} \$ 4,9$ milhões e $\mathrm{R} \$ 2$ milhōes, respectivamente.

Os projetos em parceria com prefeituras também merecem destaque por representarem uma parcela substancial do montante de projetos, que correspondem a seis acordos no valor total de $\mathrm{R} \$ 2,3$ milhōes. Adicionalmente foram assinados sete projetos de patrocínio cultural, no valor total de $\mathrm{R} \$ 417$ mil. Se somados os valores aplicados em P\&D pelas instituiçōes públicas (Receita Federal e prefeituras), o montante corresponde a R \$7,6 milhôes, ou seja, $65 \%$ do valor total dos projetos ( $\mathrm{R} \$ 11,6$ milhóes) são de origem pública. Por fim, encontram-se os convênios administrados pela Funcamp (Fundação de Desenvolvimento da Unicamp). Em 2005 foram celebrados 216 convênios, no total de $\mathrm{R} \$ 57,1 \mathrm{mi}-$ lhôes. Dentre eles, merece destaque a parceria com a Finep e com Secretaria de Estado da Educação de São Paulo, que representaram, respectivamente, $19 \%$ e $30 \%$ do montante de recursos dos convênios administrados pela Funcamp (2006).

Parece que quanto mais se tenta estimular a relação universidade-empresa, mais aumentam os gastos do governo com a P\&D universitária. Em outras palavras, quanto mais os partidários dos enfoques da NPC, da TH e da EI defendem a importância da universidade para o processo de inovação, menos as empresas se interessam por ela, e mais o governo eleva os recursos destinados à agenda de pesquisa desses partidários, a qual se dirige ao atendimento das demandas cognitivas das empresas.

\section{Conclusão}

O vínculo entre as universidades e as empresas vem sendo defendido por membros da academia que crêem no poder da inovação para se resolver os problemas socioeconômicos nacionais, com o propósito de aumentar os recursos públicos destinados 
às suas pesquisas, ainda que não haja interesse direto das empresas nesse sentido. Como indica a evolução recente da execução financeira do MCT com o Fundo Nacional de Desenvolvimento Científico e Tecnológico (FNDCT), o objetivo foi alcançado, dado o crescente aumento dos recursos públicos para a P\&D universitária (Gráfico 3).

\section{Gráfico 3 \\ Execução Financeira do FNDCT entre 2002 e 2010}

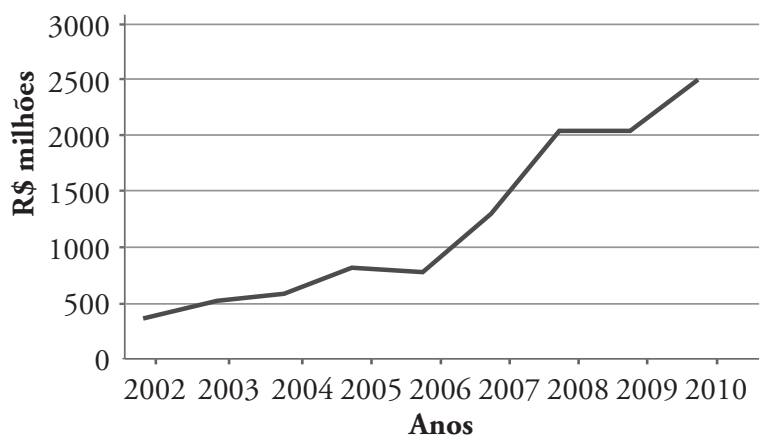

Fonte: MCT (2011).

Quanto mais o meio acadêmico defende tal relação, mais recursos públicos são destinados à universidade para que ela possa desenvolver suas pesquisas. Isso não é nenhuma novidade. Diante das perdas de recurso nos anos de 1980 e 1990, é evidente que ela buscaria o apoio de outros atores para reverter essa situação. Inserida no modo de produção capitalista, a empresa seria, então, o ator potencialmente mais forte nesse sentido. Não surpreende, portanto, que na relação universidade-sociedade, a empresa tenha se tornado sinônimo de sociedade.

Destacar a incoerência desses enfoques em relação à realidade social dos países periféricos é essencial para o entendimento do que vem ocorrendo no Brasil nesse âmbito. As perspectivas neovinculacionistas foram desenvolvidas para descrever e explicar o que ocorre em países de capitalismo avançado. Não obstante a discussão já iniciada nas décadas de 1960 e 1970 e a comprovação do perigo de assumir para nossa realidade modelos construídos para outros países - revelando as debilidades daqueles atores destacados pela EI, num primeiro momento, e pela TH e NPC, mais recentemente, no contexto brasileiro -, a relação universidade-sociedade parece que permanece orientada por esses enfoques.

Se o problema brasileiro, e dos demais países da América Latina, fosse apenas o de mimetismo de uma da agenda de pesquisa dos países de capitalismo avançado, qualquer governo nacionalista poderia resolvê-lo. Porém, como apontam Varsavsky (1969) e Dagnino (2007), a questão fundamental, que não foi tratada no espaço restrito deste artigo, refere-se à força da neutralidade da C\&T na academia.

Constatamos aqui, e isso consiste em nossa maior contribuição, indícios da relevância dos níveis governamentais na relação da universidade com a sociedade. São eles mais diretamente os responsáveis pelo atendimento das necessidades econômicas e sociais do país. Os dados mostram a importância de se refletir sobre as implicaçôes para a universidade de sua relação com as esferas governamentais.

\section{Notas}

1 Na busca foi utilizado o termo "empresa" para os campos título da produção C,T\&A, palavra-chave da produção e referência bibliográfica.

2 No sistema de busca da base de dados, restrito às páginas em português, para o número de textos e citações que fazem referência à NPC foram utilizados os termos new production of knowledge ["nova produção de conhecimento"]. Para a TH, os termos triple helix ["tripla hélice"].

3 São eles: Eixo I) Expansão e consolidação do sistema nacional de ciência, tecnologia e inovação; Eixo II) Promoção da inovação tecnológica nas empresas; Eixo III), Pesquisa, desenvolvimento e inovação em áreas estratégicas; e Eixo IV), Ciência e tecnologia para o desenvolvimento social.

\section{BIBLIOGRAFIA}

ANTONELLI, C. (2002), "Economics of knowledge and the governance of commons knowledge". Revista Brasileira de Inovação, 1: 29-48. 
BAGATTOLLI, C. (2008), Politica cientifica e tecnológica e a dinâmica inovativa no Brasil. Campinas, dissertação de mestrado, Instituto de Geociências, Unicamp.

BIATO, F.; GUIMARÃES E. \& FIGUEIREDO, M. H. (1973), A transferência de tecnologia no Brasil. Brasília, Ipea/Iplan.

BRISOLLA, S. et al. (1997), "As relações universidade-empresa-governo: um estudo sobre a Universidade Estadual de Campinas". Revista Educação e Sociedade, 61: 187-210.

CARDOSO, I. (2001). Para uma critica do presente. São Paulo, Editora 34.

CASSIOLATO, J. E. \& ZUCOLOTO, G. (2006), "Globalização das atividades de pesquisa e desenvolvimento e seus impactos em Brasil, Rússia, Índia, China e África do Sul”. Anais do XI Encontro Nacional de Economia Política, Vitória.

CATANI, A. \& OLIVEIRA, J. (1999), "A universidade pública no Brasil: identidade e projeto institucional em questão", in H. Trindade (org.), Universidade em ruinas: na república dos professores, Rio de Janeiro/Rio Grande do Sul, Vozes/Cipedes.

CHAUI, M. (1999), "A universidade em ruínas", in H. Trindade (org.), Universidade em ruinas: na república dos professores, Rio de Janeiro/Rio Grande do Sul, Vozes/Cipedes.

CIMOLI, Mario; DOSI, Giovanni; NELSON, Richard \& STIGLITZ, Joseph. (2007), "Instituiçōes e políticas moldando o desenvolvimento industrial: uma nota introdutória”. Revista Brasileira de Inovação, 6 (1): 55-85.

COSTA, I. (2003), Empresas multinacionais e capacitação tecnológica na indústria brasileira. Campinas, tese de doutorado, Instituto de Geociências, Unicamp.

DAGNINO, R. (2003), "A relação universidade-empresa no Brasil e o 'argumento da Hélice Tripla”. Revista Brasileira de Inovação, 2 (2): 267-307.

. (2004), "C\&T no nível local: uma proposta de esquerda”. Revista Espacios, Venezuela, 25 (3): 39-61.

. (2007), "Os modelos cognitivos das políticas de interação universidade empresa”. Convergência, México, 14: 95-110.
. (2010), "Apresentação: o que (nos) quer dizer a teoria crítica da tecnologia?", in R. Neder (org.), A teoria critica de Andrew Feenberg: racionalização democrática, poder e tecnologia, Brasília, CDS/UnB/Capes.

DAGNINO, R. \& THOMAS, H. (1999), "Insumos para um planejamento de C\&T alternativo". Revista Planejamento e Políticas Públicas, Brasília, 20: 89-128.

ETZKOWITZ, H. (2002), "The Triple Helix of university-industry-government: implications for policy and evaluation". Working Paper 200211. Disponível em <http://www.sister.nu>.

ETZKOWITZ, H. \& LEYDESDORFF, L. (1995), "The Triple Helix of university-industry-government relations: a loboratory for knowledge based economic development?". EASST Review, 14 (1): 14-19.

FUNCAMP (2006). "Relatório anual de atividades, 2005”. Campinas, Fundação de Desenvolvimento da Unicamp.

FURTADO, C. (1972), Análise do "modelo" brasileiro. Rio de Janeiro, Civilização Brasileira, 3. ed. - (1974), O mito do desenvolvimento econômico. Rio de Janeiro, Paz e Terra.

GIBBONS, M. et al. (1994), La nueva producción del conocimiento: la dinámica de la ciencia y la investigación em las sociedades contemporâneas. Barcelona, Ediciones Pomares-Corredor.

GOMES, E. (2001), A relação universidade-empresa no Brasil: testando hipóteses a partir do caso da Unicamp. Campinas, tese de doutorado, Instituto de Geociências, Unicamp.

GUNASEKARA, C. (2006), "Leading the horses to water: the dilemmas of academics and university managers in regional engagement". Journal of Sociology, Austrália, 42 (2): 145-163.

IBGE. (2003), Pesquisa Industrial de Inovação Tecnológica (Pintec). Brasília, IBGE.

. (2005), Pesquisa Industrial de Inovação Tecnológica (Pintec). Brasília, IBGE.

. (2008), Pesquisa Industrial de Inovação Tecnológica (Pintec). Brasília, IBGE.

INOVA UNICAMP. (2007), "Relatório de atividades, 2006”. Campinas, Unicamp/Inova.

KUPFER, D. (2010), "Pintec 2008: primeiras análises”. Jornal JC e-mail 4129, 3 nov. 
LEITE LOPES, J. (s/d), "O desenvolvimento da ciência e os povos do Terceiro Mundo". Revista Paz e Terra, 8: 18-31.

LUNDVALL, B. (2001), "Políticas de inovação na economia do aprendizado". Parcerias Estratégicas, 10: 201-218.

MEC. (2010), "Produção científica: ministro prevê inclusão do Brasil entre os dez maiores do planeta”. Disponível em <http://portal.mec. gov.br/>.

MTC. (s/d), "Indicadores". Disponível em <http:// www.mct.gov.br>. . (2010), "Principais resultados e avanços do plano de ação em ciência, tecnologia e inovação (PACTI)". Brasília, MCT. . (2011), "Relatório de gestão 2010: Fundo Nacional de Desenvolvimento Científico e Tecnológico (FNDCT)”. Rio de Janeiro, MCT.

PAIM, N. \& NICOLSKY, R. (2006), "Inovação e crescimento sustentado". Jornal JC E-mail, 8 jun.

RUIZ, A. U. (2005), "Patentes y función publica universitaria en Europa: mitos y realidades". Revista Brasileira de Inovação. Rio de Janeiro, 4 (2): 391-423.

SCHWARTZMAN, S. (2002), "A pesquisa científica e o interesse público", Revista Brasileira de Inovação, Rio de Janeiro, v. 1, n. 2.

SCIENCE AND ENGINEERING INDICATORS. (2006), "Science and engineering indicators 2006". Estados Unidos, National Science Board.

SHINN, T. (2002), "La Triple Hélice y la nueva produción del conocimiento enfocados como campos sócio-cognitivos". Redes, Buenos Aires, 9 (18): 32-54.

TERRA, J. C. \& WEISS, J. M. (2002), "Rumo à 'sociedade do conhecimento': as trajetórias do Brasil e da Coreia do Sul”. Trabalho apresentado no Simpósio de Gestão da Inovação Tecnológica, Salvador, Bahia.

THOMAS, H.; DAVYT, A. \& DAGNINO, R. (1997), "Racionalidades de la interacción universidad-empresa en América Latina (19551995)”. Espacios, 18 (1): 83-110.

TRINDADE, H. (1999). "Universidade em perspectiva: sociedade, conhecimento e poder". Revista Brasileira de Educação, 10: 5-15.
UNESCO. (2010), "Relatório Unesco sobre Ciência 2010: o atual status da ciência em torno do mundo". Brasil, Unesco.

UNICAMP. (2007), Anuário de Pesquisa da Unicamp 2007. Campinas, Unicamp.

VARSAVSKY, O. (1969), Ciencia, politica y cientificismo. Buenos Aires, Centro Editor de América Latina.

WIPO. (2010), World intellectual property indicators. Geneva, Wipo. 


\section{A RELAÇÃO UNIVERSIDADE- SOCIEDADE NA PERIFERIA DO CAPITALISMO}

\section{Rogério Bezerra da Silva}

Palavras-chave: Universidade pública; Sociedade; Empresa privada; Financiamento público.

Este artigo busca responder, com base nos Estudos Sociais da Ciência e Tecnologia (ESCT), por que a relação universidade-sociedade no Brasil vem sendo reduzida à relação universidade-empresa. Argumentamos nesse sentido que a empresa vem sendo defendida de maneira contundente no meio acadêmico com o propósito de aumentar os recursos públicos destinados às pesquisas acadêmicas, mesmo que não haja, por parte das empresas, qualquer interesse em relação à universidade. Destacamos a incoerência dos enfoques neovinculacionistas em relação à realidade social dos países periféricos, o que é essencial para o entendimento do que vem ocorrendo no Brasil nesse âmbito

\section{THE RELATIONSHIP BETWEEN UNIVERSITIES AND SOCIETY AT THE PERIPHERY OF CAPITALISM}

\section{Rogério Bezerra da Silva}

Keywords: Public university; Society; Private company; Public funding.

This article seeks to answer, based on the Social Studies of Science and Technology (SSST), why the relationship between universities and society in Brazil has been reduced to the relationship between universities and businesses. We argue, in this sense, that businesses have been strongly defended in academia in order to increase public resources intended to academic research, even though there is not, by businesses, any interest in the university. We point out the inconsistency of neoboundable approaches in relation to the social reality of the peripheral countries, which is essential to the understanding of what has been happening in Brazil in this area.

\section{LE RAPPORT UNIVERSITÉ- SOCIÉTÉ À LA PÉRIPHÉRIE DU CAPITALISME}

\section{Rogério Bezerra da Silva}

Mots-clés: Université publique; Société; Entreprise privée; Financement public.

En s'appuyant sur les Études Sociales de la Science et de la Technologie (ESST), cet article tente de répondre à la question suivante: pourquoi le rapport université-société au Brésil est entrain d'être réduit à un rapport université-entreprise ? Nos soutenons l'argument selon lequel l'entreprise est défendue de façon contondante dans le milieu académique dans le but d'augmenter les ressources publiques destinées aux recherches académiques, même en n'ayant, de la part des entreprises, aucun intérêt par rapport à l'université. Nous mettons l'accent sur l'incohérence des abordages neovinculacionistas (NT : il s'agit d'un élément de la politique des sciences et de la technologie de l'Amérique latine actuelle qui propose un changement normatif des rapports entre l'université et l'entreprise) par rapport à la réalité sociale des pays périphériques, ce qui est essentiel pour la compréhension de ce qui se passe, à ce sujet, au Brésil. 